\title{
Modelling the recruitment of tiger prawns Penaeus esculentus and $P$. semisulcatus to nursery grounds in the Gulf of Carpentaria, northern Australia: implications for assessing stock-recruitment relationships
}

\author{
Scott A. Condie ${ }^{1, *}$, Neil R. Loneragan², David J. Die ${ }^{2}$ \\ ${ }^{1}$ CSIRO Marine Research, Hobart Marine Laboratories, GPO Box 1538, Hobart, Tasmania 7001, Australia \\ ${ }^{2}$ CSIRO Marine Research, Cleveland Marine Laboratories, PO Box 120, Cleveland, Queensland 4163, Australia
}

\begin{abstract}
A prawn larval behavioural model was coupled to a hydrodynamic model of the Gulf of Carpentaria in northern Australia to provide estimates of the size of the spawning area from which nursery ground populations are drawn, referred to here as the advection envelope. We have assumed that, during the first $8 \mathrm{~d}$ after the nauplii hatch, the larvae undergo a diel vertical migration in the water column, without spending any time on the bottom. After $8 \mathrm{~d}$, larvae in waters shallower than a preset transition depth were assumed to switch to vertical migration cued by the tidal cycles-remaining on the bottom during outgoing tides, and swimming into the water column during flood tides. This tidal behaviour generated a net advection of postlarvae into the coastal zone and local estuaries. The model demonstrated that this mechanism is very efficient at accumulating larvae along the coastal zone. Changes in the timing and magnitude of the tides through the year generated a strong seasonal signal in the size and shape of the advection envelope, with typically a 2 -fold difference in the size of the envelope between October and March. However, winds had little effect on the size of the advection envelopes, and interannual variation in the size and shape of the advection envelopes was small $(<10 \%)$. The model also demonstrated that advection envelopes are very sensitive to the postlarval transition depth, which has not yet been adequately constrained by either field or laboratory studies. For example, changing the transition depth from 7 to $30 \mathrm{~m}$ typically resulted in a 2 -fold increase in the size of the advection envelope. The results of the model may also have significant implications for the management of the prawn fishery. Comparisons of the advection envelopes with the distribution of tiger prawn catches indicate regions where fishing is most likely to have an impact on the spawning stock and subsequent recruitment to the fishery. The results also suggest that there are 3 discrete substocks of Penaeus esculentus and $P$. semisulcatus in the Gulf of Carpentaria and, therefore, challenge the assumption that there is a single tiger prawn stock covering the entire region.
\end{abstract}

KEY WORDS: Larval advection · Penaeid - Postlarvae - Seagrass - Interannual variability · Seasonal variability

\section{INTRODUCTION}

The relationship between spawning stock and recruitment to the fishery is an important characteristic of exploited fish stocks. Until recently there was little con-

•E-mail: scott.condie@marine.csiro.au vincing evidence of recruitment overfishing or stock and recruitment relationships for penaeid prawns. This is thought to be due to biological characteristics of prawns, including their short life cycle, high fecundity and response to environmental variation. However, recent studies have established a relationship between spawning stock and recruitment for white shrimp 


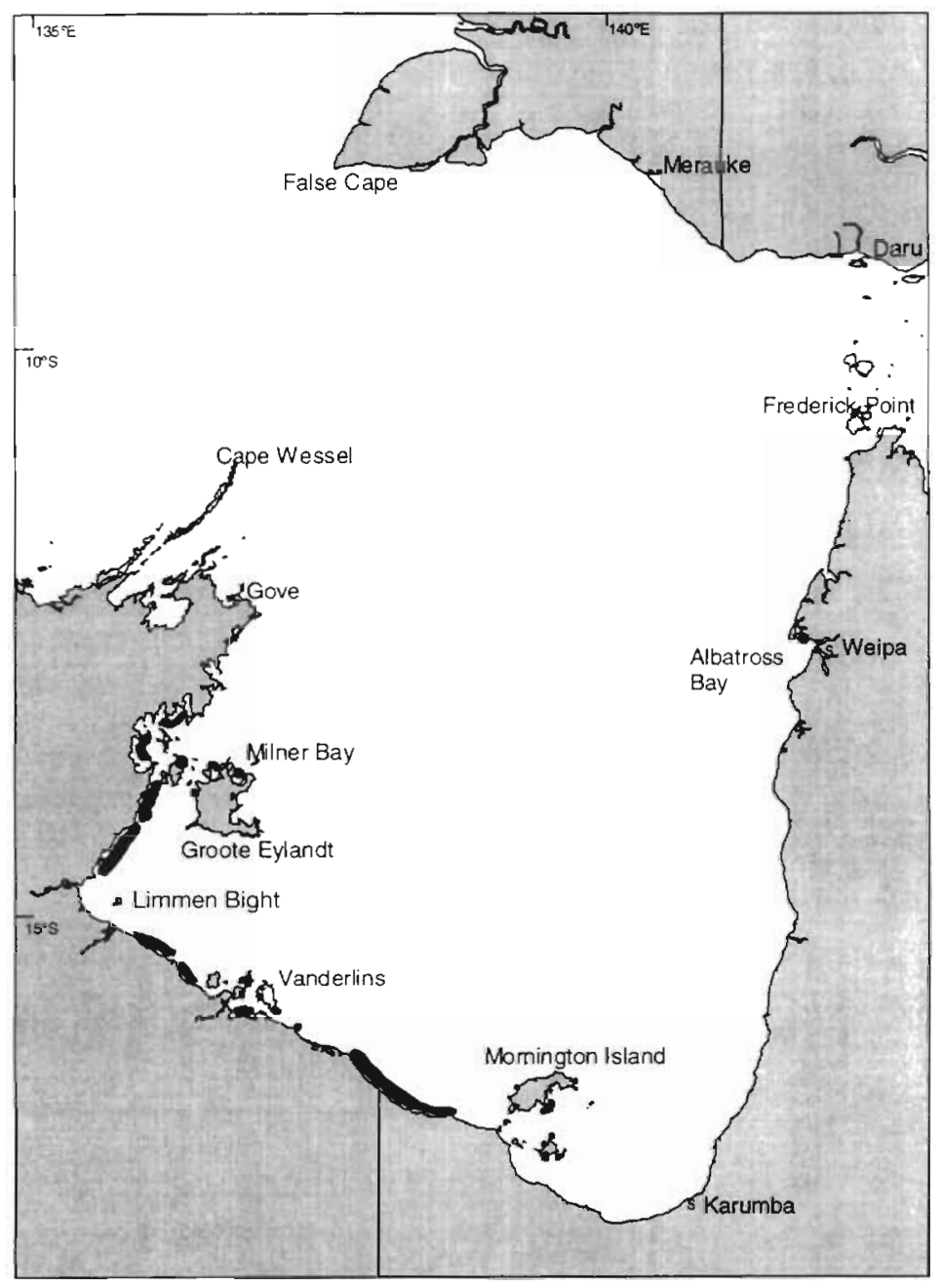

Fig. 1. Coastline map of the Gulf of Carpentaria, northern Australia, showing localities mentioned in the text, and the distribution of seagrass beds (areas in black) from Staples et al. (1985) and Poiner et al. (1987). Note that the width of the areas representing seagrass beds is not drawn to scale

Penaeus setiferus (Gracia 1996), brown tiger prawns $P$. esculentus and grooved tiger prawns $P$. semisulcatus (Penn \& Caputi 1986, Penn et al. 1995, Wang \& Die 1996). The last 2 species comprise about $40 \%$ of the total catch from Australia's most valuable commonwealth fishery, the Northern Prawn Fishery (NPF). In considering the relationship between spawning stock and recruitment for this fishery, both species of tiger prawns have been assumed to come from unit stocks, despite the fact that this fishery extends across about $6000 \mathrm{~km}$ of coastline in northern Australia.

Excessive fishing on tiger prawns by the NPF fleet in the 1980 s caused a significant decline in the abundance of spawners and recruits (Wang \& Die 1996). The protection of spawning tiger prawns has therefore become a critical issue for the managers of the NPF. On the basis of the information available in the 1980s, the main fishing grounds were thought to coincide with the areas where tiger prawns spawned and hence any substantial reductions of fishing on spawners were thought to be at the cost of closing prime fishing grounds. This led to the present management strategy that seeks to protect pre-spawning tiger prawns from fishing by reducing effort through a seasonal (June-July) closure.

The above conclusions were based on the assumption that all spawning females contributed equally to recruitment. However, recent work suggests that spawning may be more successful close to the shallow water seagrasses that serve as nursery grounds (Crocos \& van der Velde 1995, Haywood et al. 1995, Loneragan et al. 1998). The distribution of seagrasses in the Gulf of Carpentaria is limited to the southern and western shorelines, and Albatross Bay in the northeast near Weipa (Poiner et al. 1987, Fig. 1). Only those larvae that reach these beds are likely to survive, grow and eventually recruit to the fishery (Staples et al. 1985). Any index of effective spawning (sensu Crocos \& van der Velde 1995) should therefore include the likelihood of larvae recruiting to the shallow seagrass beds.

There is strong evidence that the transport of prawn larvae to coastal nursery habitats in northern Australia is controlled by interactions between tidal flows and the vertical migration of the larvae (e.g. Rothlisberg et al. 1983, 1996). Postlarvae remain close to or on the seabed during outgoing tides and then swim into the water column during the flood tide. This behaviour is presumably triggered by the pressure changes associated with tidal changes in water depth. It appears to provide an efficient means of transporting larvae toward the shoreline, without the need for chemical cues such as salinity gradients (Hughes 1969, Rothlisberg et al. 1995).

This paper describes a modelling study aimed at identifying the spawning regions from which tiger prawn larvae can be transported to their seagrass bed nurseries in the Gulf of Carpentaria. The results of this study provide one means of identifying stock boundaries for tiger prawns within the NPF, hence enabling the stock-recruitment approach of Wang \& Die (1996) to be extended from the whole of the NPF to individual regional stocks.

The general modelling approach is similar to that adopted by Rothlisberg et al. (1996) in that a larval behaviour model has been incorporated into a hydro- 
dynamic model of the Gulf circulation. However, the current model differs from the earlier model in 3 fundamental aspects. Firstly, it extends the coverage of the model from the Weipa region in the northeastern Gulf of Carpentaria to the entire Gulf of Carpentaria. This incorporates the extensive seagrass beds and their associated tiger prawn fisheries in the south and west, and increases the total seagrass area in the bounds of the model by more than 100 times. Secondly, wind forcing has been incorporated into the hydrodynamic model. This introduces interannual variability into the larval advection trends. Thirdly, the vertical migration of larvae in Rothlisberg et al. (1996) consisted of discrete jumps between 2 preset depths. In the current model, larvae swim in a continuous path through the water column, while being advected and dispersed by the prevailing flow. This results in more realistic vertical population distributions.

\section{MATERIAL AND METHODS}

Hydrodynamic model. Flow in the Gulf of Carpentaria was simulated using the 3-dimensional nonlinear hydrodynamic model referred to as MECO (Model of Estuaries and Coastal Oceans). This model has previously been applied to a range of estuarine and shelf systems, the best documented being Port Philip Bay in southeastern Australia (Walker 1996). The numerical grid was rectangular with 76 by 104 cells in the horizontal and 12 cells in the vertical. Each cell measured $10 \mathrm{~km}$ by $10 \mathrm{~km}$ in the horizontal, while cell height increased with depth (interfaces at depths of $0,3,6,9$, $12,15,20,25,30,40,50,60$, and $70 \mathrm{~m}$ ). The entire grid was also rotated $30^{\circ}$ clockwise in the horizontal to match the geometry of the Gulf and provide straight open boundaries between Cape Wessel and False Cape in the west and Frederick Point and Daru in the east (Fig 1). Where necessary the coastal geometry was tuned slightly to ensure realistic exchange across the heads of estuaries and inlets into which larvae are advected.

The flow in the Gulf was forced by surface winds, and tidal surface elevations at the open boundaries. Surface heat fluxes were only incorporated in a small number of runs designed to test the influence of temperature stratification. Synoptic winds were interpolated from data from the European Centre for Medium-Range Weather Forecasts (ECMWF). This consists of daily averaged estimates of wind speed with a $2.5^{\circ}$ spatial resolution, and therefore does not resolve smaller scale or diurnal processes such as localized storms and sea-breezes. The tides are by far the most significant forcing in the Gulf and their incorporation into the model is now discussed.
Tidal heights incorporating the $\mathrm{M}_{2}, \mathrm{~S}_{2}, \mathrm{~K}_{1}$ and $\mathrm{O}_{1}$ components were specified across Torres Straight by linearly interpolating from Frederick Point to Daru and across the Arafura Sea by linearly interpolating from Cape Wessel to False Cape. Tidal station data is available at all of these locations except False Cape (Australian National Tide Tables 1996). The tidal harmonic constants at False Cape were therefore adjusted to provide realistic tides at 8 other locations around the Gulf coast. This approach has been adopted in a number of previous studies (Church \& Forbes 1981, Wolanski 1993, Rothlisberg et al. 1996). However, the final fit to the observed tides is also dependent on the friction in the model, which is a function of the parameterisation of diffusion and resolution of bathymetry. Any errors from this source cannot usually be corrected by modifying the tides at the station without tidal data, i.e. False Cape. The False Cape harmonic constants which provided the best tidal estimates in MECO (Table 1) are similar to those obtained by Church \& Forbes (1981), except that the amplitude of $\mathrm{S}_{2}$ is larger and the phases of $\mathrm{M}_{2}$ and $\mathrm{S}_{2}$ lag slightly. The resulting phase difference between Cape Wessel and False Cape is approximately $100^{\circ}$, which falls between the estimates of $130^{\circ}$ by Church \& Forbes (1981) and $30^{\circ}$ by Wolanski (1993).

The advection of penaeid prawn larvae is most strongly influenced by tidal motions within the coastal zone (Rothlisberg et al. 1995). The hydrodynamic model was therefore tuned using tidal measurements from various locations around the coastline. Apart from a slight phase lag, the agreement between tides predicted by the model (tuned using the False Cape harmonic constants: Table 1) and measured tides is very good at Merauke (Fig. 2). While the agreement appears less convincing at Weipa, it should be noted that the gauge is situated within the estuary and may be strongly influenced by local bathymetry and coastline geometry unresolved by the model. This suggestion is supported by the improved agreement at Karumba, in the southeastern Gulf. The tidal signal propagates clockwise around the gulf, and by the time it reaches Milner Bay in the western Gulf, there is a tendency for the model to underestimate tidal amplitudes by around 15\%. The agreement improves

Table 1. Tidal amplitudes $(H)$ and phase $(g)$ at False Cape, Papua New Guinea. Numbers in parentheses are values calculated by Church \& Forbes (1981)

\begin{tabular}{|lcc|}
\hline Constituent & $H(\mathrm{~m})$ & $g$ (degrees) \\
\hline $\mathrm{M}_{2}$ & $0.9(0.9)$ & $320(340)$ \\
$\mathrm{S}_{2}$ & $0.4(0.2)$ & $40(120)$ \\
$\mathrm{K}_{1}$ & $0.8(0.8)$ & $125(125)$ \\
$\mathrm{O}_{1}$ & $0.8(0.8)$ & $60(60)$ \\
\hline
\end{tabular}



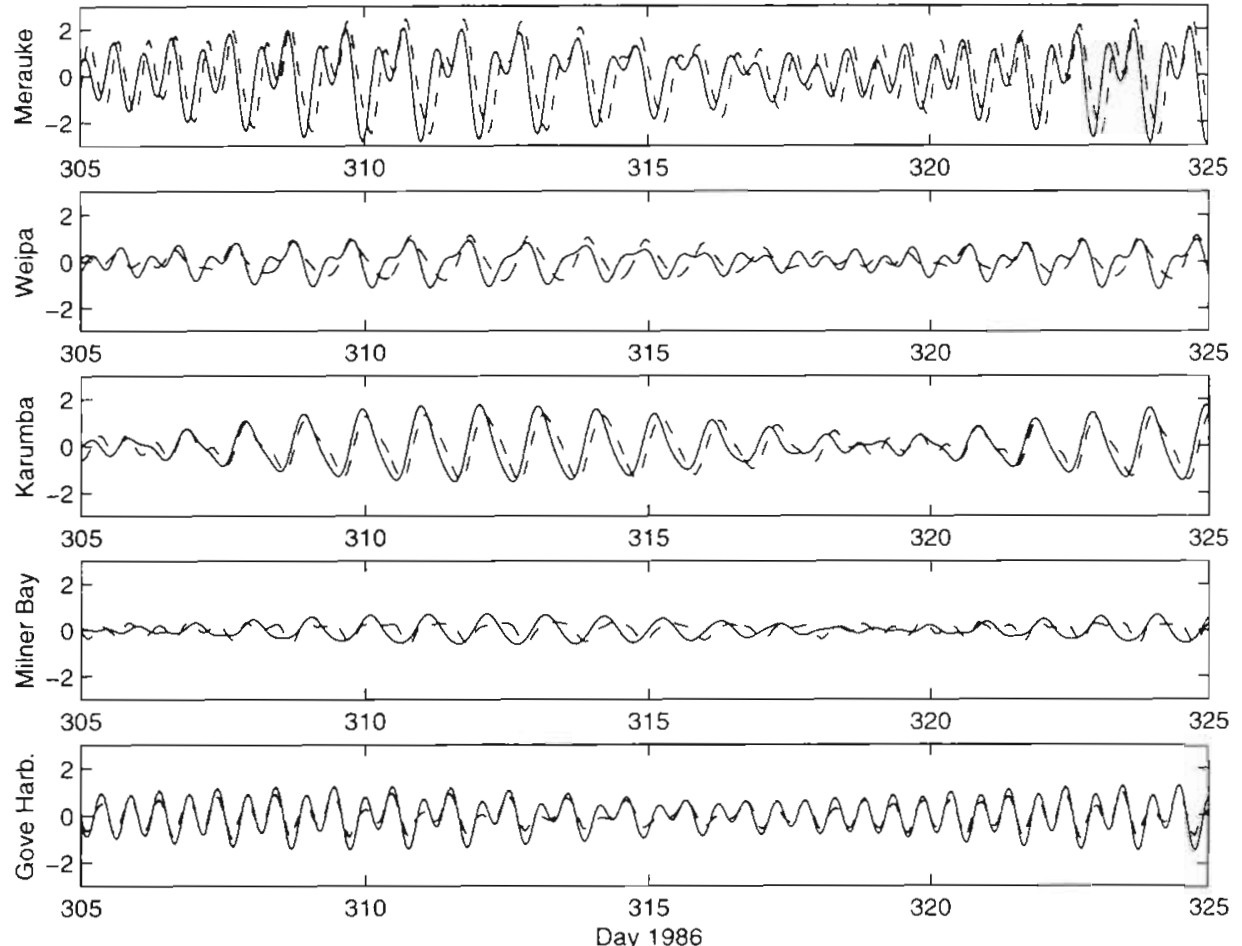

Fig. 2. Time series of tidal heights determined from the local tidal harmonics (solid lines) and the hydrodynamic model (dashed lines) at 5 locations on the Gulf of Carpentaria coastline markedly again at Gove Harbour (northwestern Gulf), as the influence of the model boundary forcing at Cape Wessel becomes more significant.

While there have been very few direct observations of currents within the Gulf, the model agrees reasonably well with the observed current signal. For example, time series of model current vectors (not shown) are almost identical to those observed by Wolanski (1993), except that model current speeds are overestimated by 5 to $10 \%$. The low frequency component of the currents is much more difficult to replicate, with model estimates typically a factor of 2 or more smaller than those observed by Wolanski (1993). This is not surprising given the limited resolution of the wind field and the absence of any low frequency component in the boundary forcing. Fortunately, the behaviour of the tiger prawn larvae ensures that their advection is strongly dominated by tidal motions, which, for such a large shallow system, are represented remarkably well.

Larval model. Actively swimming particles representing the prawn larvae were incorporated into the hydrodynamic model. At the start of each month they were seeded onto a regular $5 \mathrm{~km}$ grid covering the entire Gulf of Carpentaria. They were then allowed to swim vertically through the water column, while also being advected and diffused by the water circulation. Diffusion was via a random walk process, which was statistically equivalent to a horizontal diffusivity of $1 \mathrm{~m}^{2} \mathrm{~s}^{-1}$ and a vertical diffusivity dependent on the shear in the water column (Csanady 1982). Based on field measurements, it was also assumed that for the first $8 \mathrm{~d}$ the larvae migrate with a diel cycle, swimming gradually toward the bottom from midnight to midday and towards the surface from midday to midnight. This behaviour results in an accumulation of larvae toward the bottom during the day and toward the surface during the night, as found by field sampling (Rothlisberg 1982) and documented for other species such as blue crab megalopae (Olmi 1994). Under the influence of the background flow, a constant vertical swimming speed of $0.4 \mathrm{~cm} \mathrm{~s}^{-1}$ resulted in a net migration rate of around $1 \mathrm{~m} \mathrm{~h}^{-1}$, which yielded quite realistic diel trends in vertical larval distribution.

Beginning on the ninth day, the diel migration pattern for all larvae located in water shallower than a specified transition depth was assumed to change to a new swimming behaviour synchronised with the tidal cycle. Specifically, the postlarvae remain on the seabed during the outgoing tide, then swim into the water column at the start of the flood tide in response to increasing hydrostatic pressure. There is significant uncertainty in the duration of each swimming event and we assumed that the postlarvae swim for the entire flood tide before settling on the seabed. The vertical swimming speed for postlarvae was set at $8.0 \mathrm{~cm} \mathrm{~s}^{-1}$, although recruitment envelopes were again insensitive to swimming speed.

The effect of uncertainties in the hydrodynamics on larval advection distances can be estimated as follows. 
Table 2. Summary of parameters for wind, stratification of the water column and the transition depth used in the model runs to calculate larval advection envelopes. Synoptic winds were interpolated from the European Centres for Medium-Range Weather Forecasts (ECMWF)

\begin{tabular}{|ccccc|}
\hline Run no. & Run period & Winds & Stratification & Transition depth (m) \\
\hline 1 & Jan $1986-$ Dec 1990 & ECMWF & None & 15 \\
2 & Oct 1990 & No wind & None & 15 \\
3 & Oct 1990 & ECMWF & Yes & 15 \\
4 & Oct 1990 & ECMWF & None & 7 \\
5 & Oct 1990 & ECMWF & None & 20 \\
6 & Oct 1990 & ECMWF & 30 \\
\hline
\end{tabular}

During the larval stage, advection is determined by low frequency motions (weekly timescale). Beginning with the cross-shore component, weekly averaged velocities are estimated from limited data to be around $2 \mathrm{~cm} \mathrm{~s}^{-1}$ in the coastal zone (Wolanski 1993). Over the $8 \mathrm{~d}$ of the larval stage, this corresponds to an advection distance of $14 \mathrm{~km}$. Because the model has a quite limited capacity to predict low frequency velocities, a reasonable estimate of the uncertainty in the offshore extent of the envelope during the first $8 \mathrm{~d}$ is perhaps 10 $\mathrm{km}$. During the next stage of behaviour (cued by the tidal cycle), mean onshore velocities are less than 10 $\mathrm{cm} \mathrm{s}^{-1}$ and errors should be comparable to those in tidal height $(\sim 10 \%)$. Therefore, if flood tides operate for half of the time, the uncertainty in advection after $20 \mathrm{~d}$ of tidally cued vertical migration is around $9 \mathrm{~km}$, similar to the uncertainty during the first stage of diel behaviour. Since tidal advection is mainly associated with the cross-shore component, uncertainties in the alongshore direction have been based purely on the low frequency motions. For $28 \mathrm{~d}$ averaged alongshore velocities, a value of $2 \mathrm{~cm} \mathrm{~s}^{-1}$ again appears to be realistic (Wolanski 1993). Assuming that this velocity operates continuously over the first $8 \mathrm{~d}$, and then during flood tide over the following $20 \mathrm{~d}$, gives an advection distance of around $30 \mathrm{~km}$. The limited skill of the model with respect to low frequency motions again suggests that the uncertainty in the alongshore extent of the envelope is not very much less than this value and might be nominally set at say $20 \mathrm{~km}$.

Runs of the combined hydrodynamic-larval model covered the 5 yr period from January 1986 to December 1990. By re-seeding larvae every month, these runs provided information on both seasonal and interannual variability in the size and shape of the advection envelopes. (Table 2). For each month over the 5 yr period, ECMWF winds were used as inputs to the model, the water column was assumed to be homogenous and the transition depth for the change in larval behaviour from vertical migration cued by diel to tidal cycles was $15 \mathrm{~m}$. Sensitivity of the model to specific environmental conditions and behavioural characteristics was tested for
1 mo (October 1990) by using different combinations of wind (ECMWF winds, or no wind), stratification (homogenous or stratified) and transition depths (7, 15, 20 and $30 \mathrm{~m}$ ) (Table 2). Although some spawning occurs throughout the year, October is the month of consistently high spawning activity in the Weipa region (Crocos and van der Velde 1995)

The advection envelope and effective spawning. The most important aspect of the recruitment issue from a fisheries perspective is identifying the spawning area from which the nursery habitats (seagrass beds and mangroves) draw their maturing larval populations. This is what Rothlisberg et al. (1996) referred to as the advection envelope. While the size of the envelope will clearly grow with time, mortality rates are very high for larvae not reaching the beds within a month after spawning. Most of the results are therefore presented in terms of recruitment envelopes at $28 \mathrm{~d}$. The size of the advection envelopes has been calculated for the 4 main regions of seagrass in the Gulf of Carpentaria. The mean, standard deviation and coefficient of variation for the advection envelopes in each region were calculated for the months of 1 yr (1986), and over 5 yr for 1 mo (October).

The increasing size of the advection envelope over time is not a direct indicator of the number of postlarvae reaching the seagrass beds. Mortality rates also need to be taken into account, including major differences between the offshore and nursery ground rates. Offshore estimates typically exceed $70 \% \mathrm{wk}^{-1}$, while those in the nurseries fall within the range of 10 to $25 \%$ $w^{-1}$ (Dall et al. 1990, O'Brien 1994). Mortality could be crudely represented in the model by assuming that spawning is uniform over the entire advection envelope and multiplying the population in each grid cell by a decaying exponential function based on rates of $70 \% \mathrm{wk}^{-1}$ offshore and $14 \% \mathrm{wk}^{-1}$ on the seagrass.

The NPF fleet targets large mature tiger prawns on the areas of the fishing ground where they are most abundant (Somers 1994). Therefore the distribution of catches reported in the commercial fishery logbooks approximates that of tiger prawn spawners. In the NPF, 
daily catches are reported by fishers for $6^{\prime} \times 6^{\prime}$ grids. Commercial fishers do not separate the 2 tiger prawn species, but the catch by species can be estimated from the location of the catch (Somers 1994). For each species of tiger prawn, the spawning area for a specified month (October 1990) was assumed to include all grids with the highest catches in that month. The combined catch within these grids was constrained to be $80 \%$ of the total monthly catch of tiger prawns. To determine those areas where spawning was effective, the distribution of spawning was overlayed on the advection envelopes calculated for a range of postlarval transition depths. Any grid box within the spawning region containing at least 1 of the advection envelope points was then defined as forming part of the effective spawning region.

\section{RESULTS}

\section{Development of the advection envelope}

Postlarval behaviour controlled by tidal cueing was triggered at the start of Day 9 in waters less than the specified transition depth $(15 \mathrm{~m})$. This initiated the efficient transport of postlarvae toward the coastline, where they accumulated (Fig. 3). The resulting discontinuity in the concentration of particles at the $15 \mathrm{~m}$ depth contour was clearly evident on Day 9 (Fig 3a). Smaller numbers of larvae from deeper water continued to drift past the transition depth and begin the postlarval migration. This provided a continuously decreasing flux of postlarvae into the nursery grounds (Fig. 3c,d)

The advection envelopes indicate that some larvae had already reached the seagrass beds by Day 9 (Fig. 4a). Between Days 9 and 14, the advection envelopes expanded rapidly away from the seagrass beds in both the offshore and alongshore directions (Fig. 4b). However, by Day 21 most of the postlarvae shallower than the transition depth had reached the coastal zone and further expansion in the advection envelopes tended to be more gradual (Fig. 4c,d).

The area of the advection envelopes for Weipa was very small $\left(<100 \mathrm{~km}^{2}\right)$ until Day 8 and then increased to an asymptote of about $1400 \mathrm{~km}^{2}$ by Day 20 (Fig. 5a). In contrast, the size of the envelopes in the other regions increased more rapidly after Day 8 than that at Weipa, and continued to increase after Day 20, particularly in the Mornington Island region. Thus, the area of the advection enve- lope in the Mornington Island region increased from about $1000 \mathrm{~km}^{2}$ on Day 8 to $6000 \mathrm{~km}^{2}$ on Day 20 and $8000 \mathrm{~km}^{2}$ on Day 28 (Fig. 5a).

When typical mortality rates were included in the model, the number of individuals in the population on the seagrass beds peaked approximately $10 \mathrm{~d}$ after spawning (Fig. 5b), then declined to around 10 to $20 \%$ of the zero mortality population after $28 \mathrm{~d}$ (cf. Fig. 5a, b). Mortality is relatively higher at Weipa and Mornington Island (Fig. 5b) than in the other regions because the advection envelopes continue to grow over a longer period (Fig. 5a), which exposes more of their larval populations to high offshore mortality rates.

\section{Seasonal variability}

There was clearly considerable seasonal variation in the $28 \mathrm{~d}$ advection envelopes, with envelope areas in all regions varying by almost a factor of 2 (Figs. $6 \& 7 \mathrm{a}$ ). For example, at Weipa the minimum area of the envelope in 1986 was $900 \mathrm{~km}^{2}$ in January compared with the maximum of $1950 \mathrm{~km}^{2}$ in September (Fig. 7a). In contrast to Weipa, the maximum area of the advection envelopes in the Mornington Island, Limmen Bight and Groote Eylandt regions were found in December and January (Fig. 7a). The coefficient of variation for
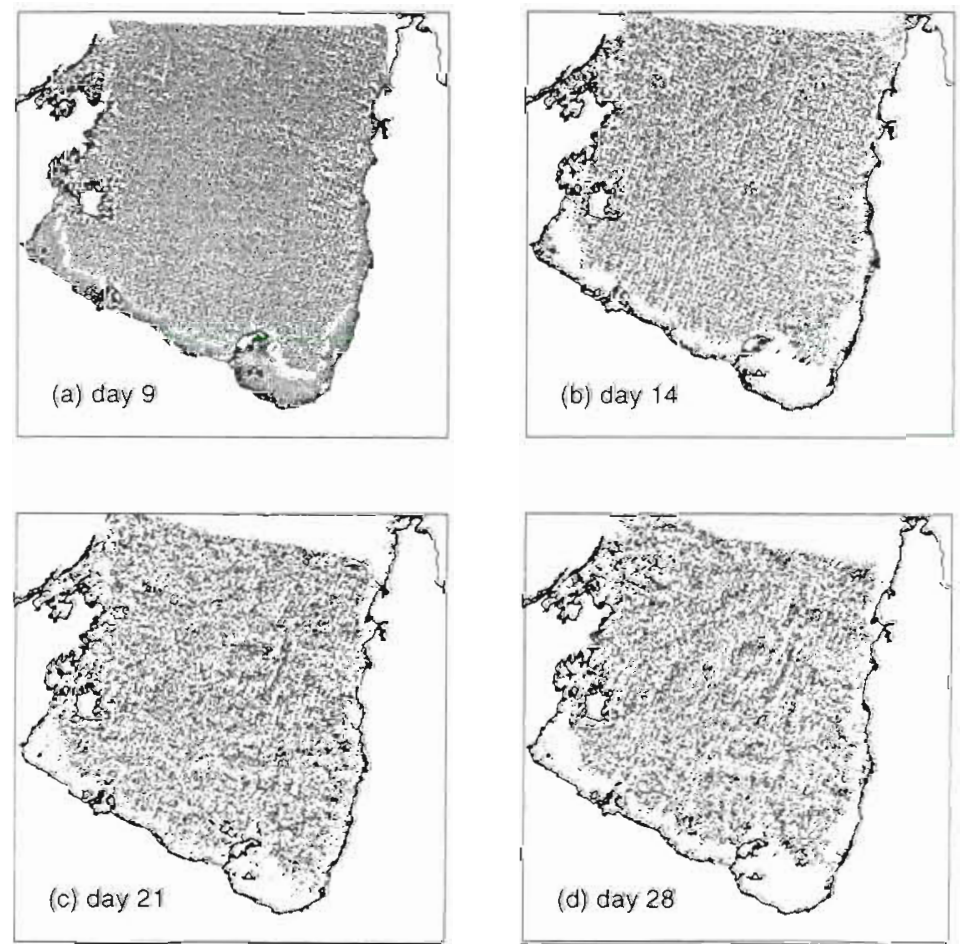

Fig. 3. Distribution of all particles seeded in the Gulf of Carpentaria (a) 9, (b) 14, (c) 21 and (d) $28 \mathrm{~d}$ after a spawning in October 1990. Note that particles accumulate on the coastline 
the area of the advection envelope in each region was between 15 and $20 \%$.

Envelopes for the 2 main spawning months of March and October also differ substantially. For example, the area of the envelope around Weipa for March $\left(1375 \mathrm{~km}^{2}\right)$ was significantly below the annual average, while for October $\left(1700 \mathrm{~km}^{2}\right)$ it was above average. This was because the envelope in October extended further to the northwest from Weipa, in agreement with the model of Rothlisberg et al. (1996). In other regions of the Gulf, envelopes extended further offshore on the southern coastline and around Mornington Island in October compared with March. However, around Groote Eylandt, the envelopes were smaller in October than in March. There also appeared to be significant advection of postlarvae from south of Groote Eylandt during March, consistent with strong clockwise circulation during flood tides.

\section{Interannual variability}

Because the larval advection is forced predominantly by the tides, interannual variation in the advection envelopes for October
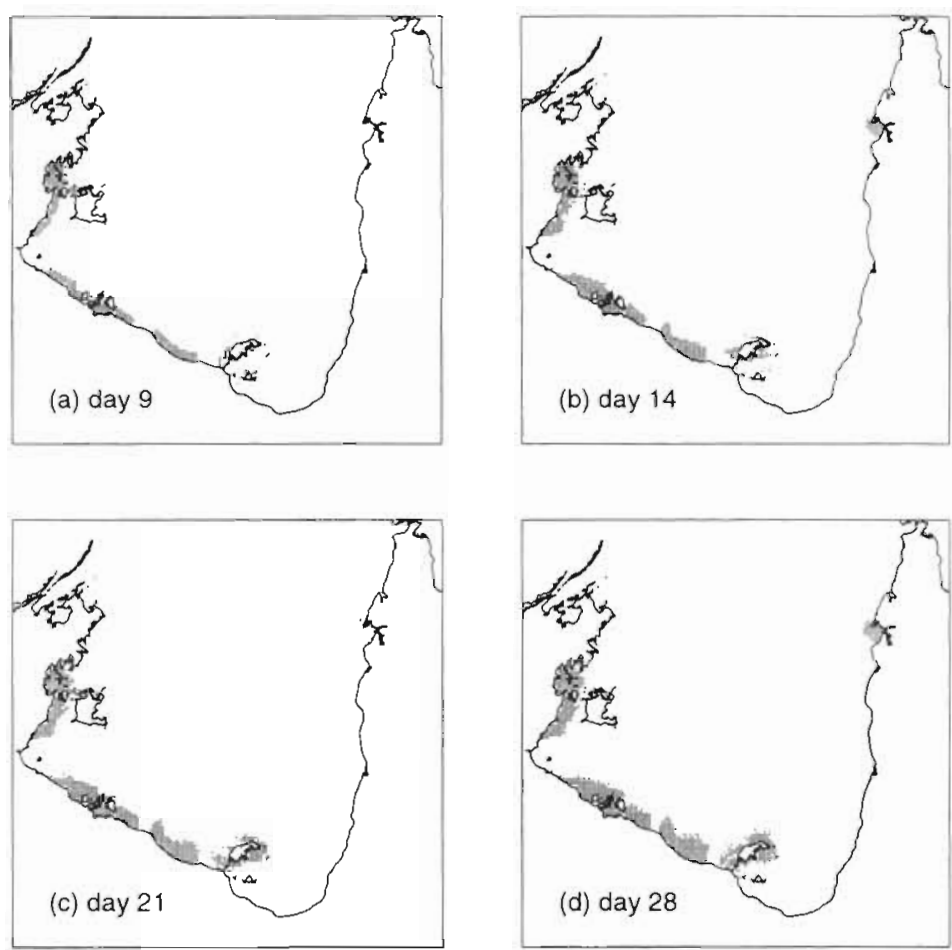

Fig. 4. Advection envelopes of postlarvae reaching seagrass beds in the Gulf of Carpentaria (a) 9 , (b) 14 , (c) 21 and (d) 28 d after a spawning in October 1990. Note that envelopes have not been determined for the northwest Gove region because the extent of seagrass coverage in this region is not known
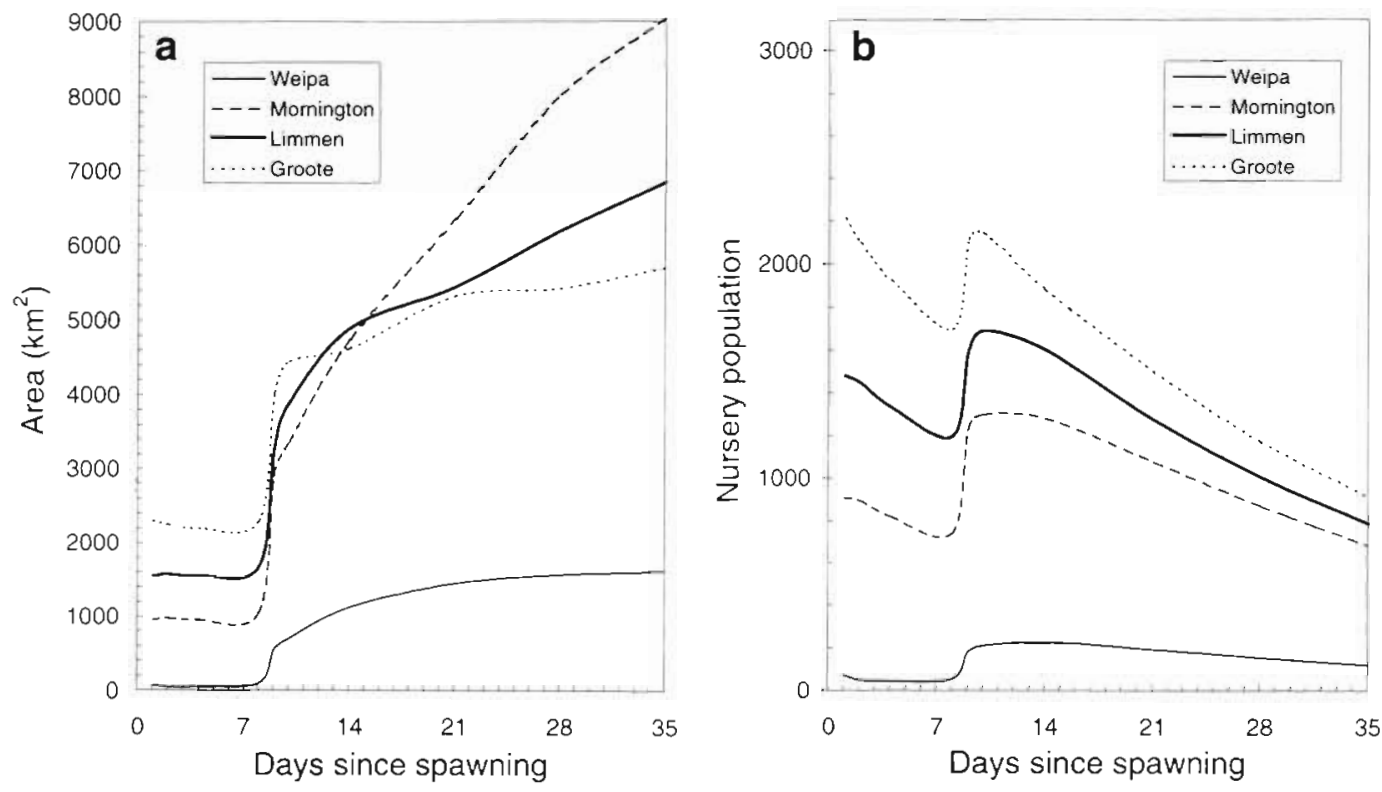

Fig. 5. (a) Changes in the area of the advection envelopes for each of the major tiger prawn fishery regions in the Gulf of Carpentaria at different times after a spawning in October 1990. Initial envelope area is based on seagrass beds with areas of: $7 \mathrm{~km}^{2}$ for the Weipa region; $170 \mathrm{~km}^{2}$ in the Mornington Island region; $280 \mathrm{~km}^{2}$ for the Limmen Bight-Vanderlins region; and $440 \mathrm{~km}^{2}$ for the Groote Eylandt region (Poiner et al. 1987). The area of seagrass is not known for the Gove region. (b) The relative number of individuals in modelled populations within the major tiger prawn fishery regions in the Gulf of Carpentaria at different times after a spawning in October 1990 when larval and postlarval mortality is included. Numbers have been scaled such that 

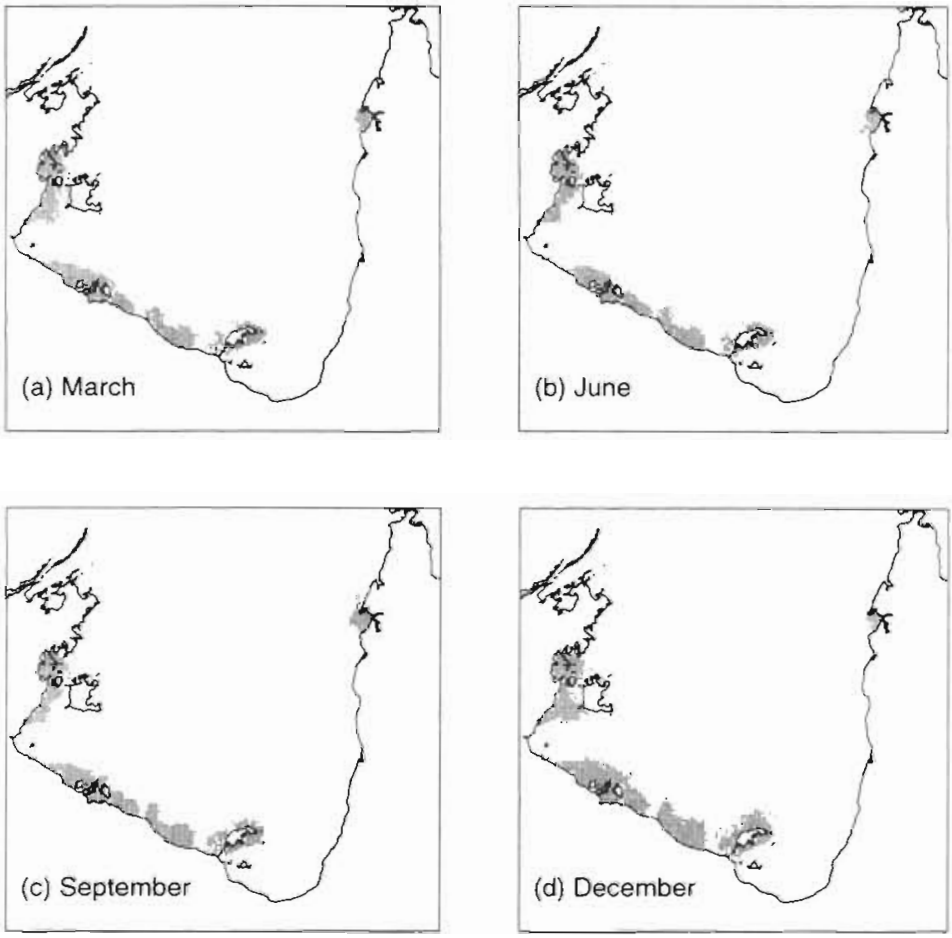

Fig. 6. Seasonal changes for the $28 \mathrm{~d}$ advection envelopes in 1986 illustrated by the advection envelopes for (a) March, (b) June, (c) September and (d) December

was much less than the seasonal fluctuations (cf. Fig. $7 a, b)$. The position of the outer edge of the envelope was always within $5 \mathrm{~km}$ of the average position for any given month. The area of the October advec-

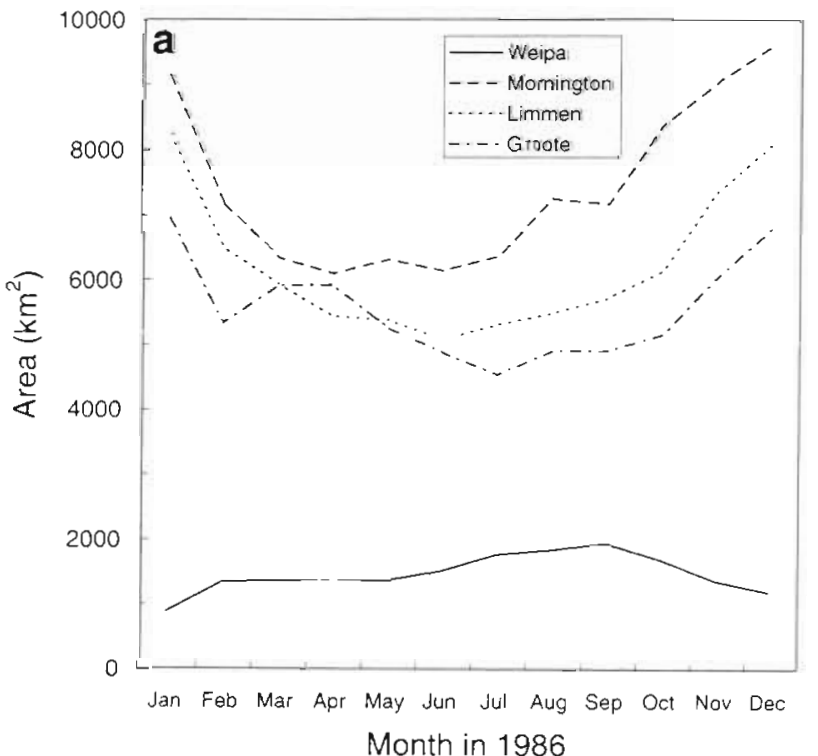

tion envelope at Weipa ranged from only $1575 \mathrm{~km}^{2}$ in 1990 to $1800 \mathrm{~km}^{2}$ in 1988 . The coefficient of variation for the envelope size in October was only 4 to $6 \%$ in each region and over the Gulf as a whole.

\section{Sensitivity to wind, stratification and postlarval transition depth}

When no winds were used in the model, only minor changes in the size and shape of the advection envelope were found compared with the standard model run (compare Fig. 8a and Fig. 4d). For example, the envelope around Weipa is slightly broader to the north, but still equal in area to the October average.

During summer the central Gulf is characterised by significant levels of stratification (Forbes 1984, Somers \& Long 1994). However, because of low turbidity levels, the surface mixed layer generally extends down to 20 or $30 \mathrm{~m}$, so that the coastal zone remains well mixed. The influence of stratification with these characteristics has been examined by incorporating solar radiation and surface heat losses (radiative, sensible and evaporative) into the model. While no changes were made to the specified larval characteristics, stratification tends to reduce turbulent mixing and may enhance wind-driven surface transports. However, these effects do not

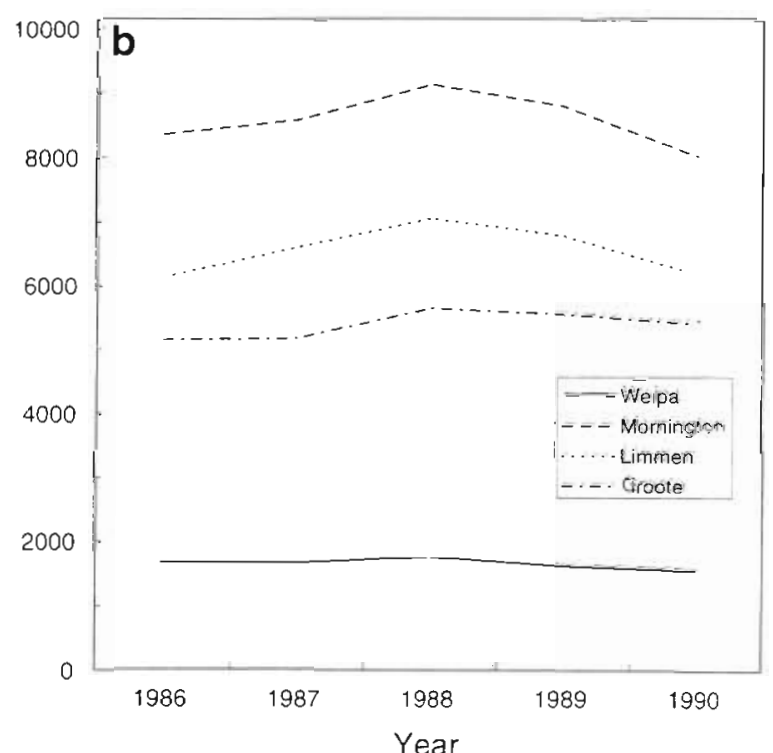

Fig. 7. The surface area of advection envelopes associated with each fishery region for (a) each month in 1986 and (b) the month of October from 1986 to 1990 

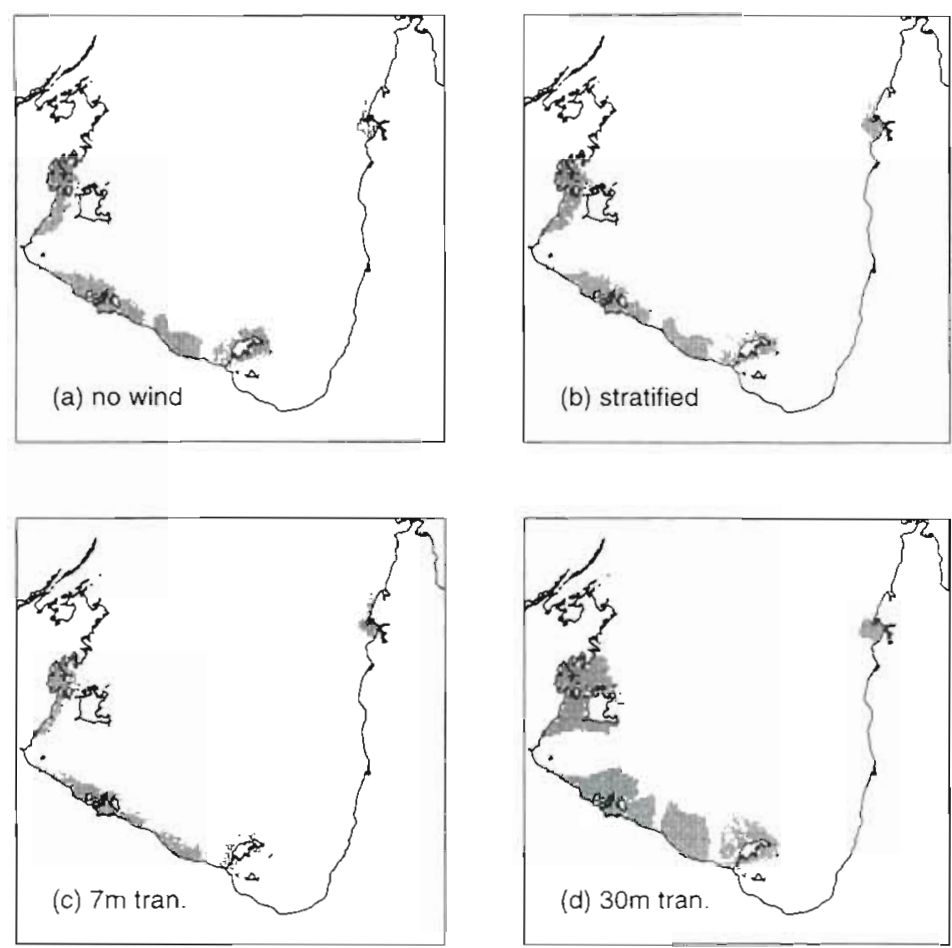

Fig. 8. The $28 \mathrm{~d}$ advection envelopes for October 1990 incorporating (a) zero wind, (b) thermal stratification, (c) a transition depth of $7 \mathrm{~m}$ and (d) a transition depth of $30 \mathrm{~m}$. The standard October 1990 run is shown in Fig. $4 d$

appear to significantly affect the size and shape of the advection envelopes (compare Fig. $8 \mathrm{~b}$ and Fig. 4d). The area of the Weipa envelope is unchanged while there is a contraction in the envelope around Morning-

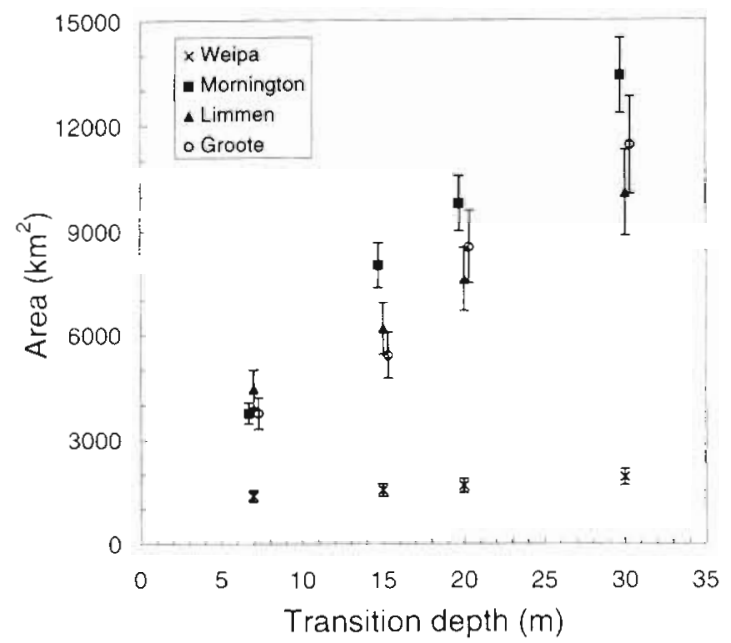

Fig. 9. Surface area of advection envelopes associated with each fishery region $28 \mathrm{~d}$ after an October 1990 spawning, as a function of postlarval transition depth. Error bars are based only on uncertainties in current velocities ton Island. Less realistic stratification penetrating into the upper few metres and horizontally into coastal zone (not shown) produced a significant expansion of the envelope north of Groote Eylandt, but no other major effects.

The final factor to be varied was the transition depth for postlarval behaviour (Fig. 8c, d). Not surprisingly, the advection envelopes expand offshore to meet the transition depth Around Weipa this results in the 28 day envelope increasing by around $29 \mathrm{~km}^{2}$ or $2.5 \%$ each time the transition depth is increased by $1 \mathrm{~m}$ in the model (Fig. 9). These rates tend to be much higher in the other regions, in some cases exceeding 10\%. Changes in the transition depth clearly represent the largest source of uncertainty in model estimates of the advection envelope size.

\section{Effective spawning areas}

The spawning areas defined by those grids supporting $80 \%$ of the catch represented approximately $20 \%$ of all grids fished for either species of tiger prawn. This reflects the high degree of aggregation of tiger prawns in the NPF. The area of effective spawning, based on the overlap of spawning areas and advection envelopes, was very sensitive to the postlarval transition depth (Table 3). Less than $3 \%$ of the total tiger prawn catch of October 1990 was caught in this area when the transition depth for postlarvae was set to $7 \mathrm{~m}$. If this depth is set to $30 \mathrm{~m}, 57 \%$ of the catches of Penaeus esculentus and $30 \%$ of $P$, semisulcatus, are found within the effective spawning area. The effec-

Table 3. Catch of the 2 species of tiger prawns in October 1990 within and outside the advection envelope for different transition depths

\begin{tabular}{|lccc|}
\hline $\begin{array}{l}\text { Depth } \\
(\mathrm{m})\end{array}$ & $\begin{array}{c}\text { Catch (tonnes) } \\
\text { within } \\
\text { envelope }\end{array}$ & $\begin{array}{c}\text { Catch (tonnes) } \\
\text { outside } \\
\text { envelope }\end{array}$ & $\begin{array}{c}\text { \% of catch } \\
\text { within } \\
\text { envelope }\end{array}$ \\
\hline Penaeus esculentus & & \\
7 & 5 & 199 & 2 \\
15 & 18 & 186 & 9 \\
20 & 39 & 164 & 19 \\
30 & 116 & 88 & 57 \\
Penaeus semisulcatus & & \\
7 & 11 & 532 & 2 \\
15 & 26 & 517 & 5 \\
20 & 60 & 483 & 11 \\
30 & 163 & 380 & 30 \\
\hline
\end{tabular}



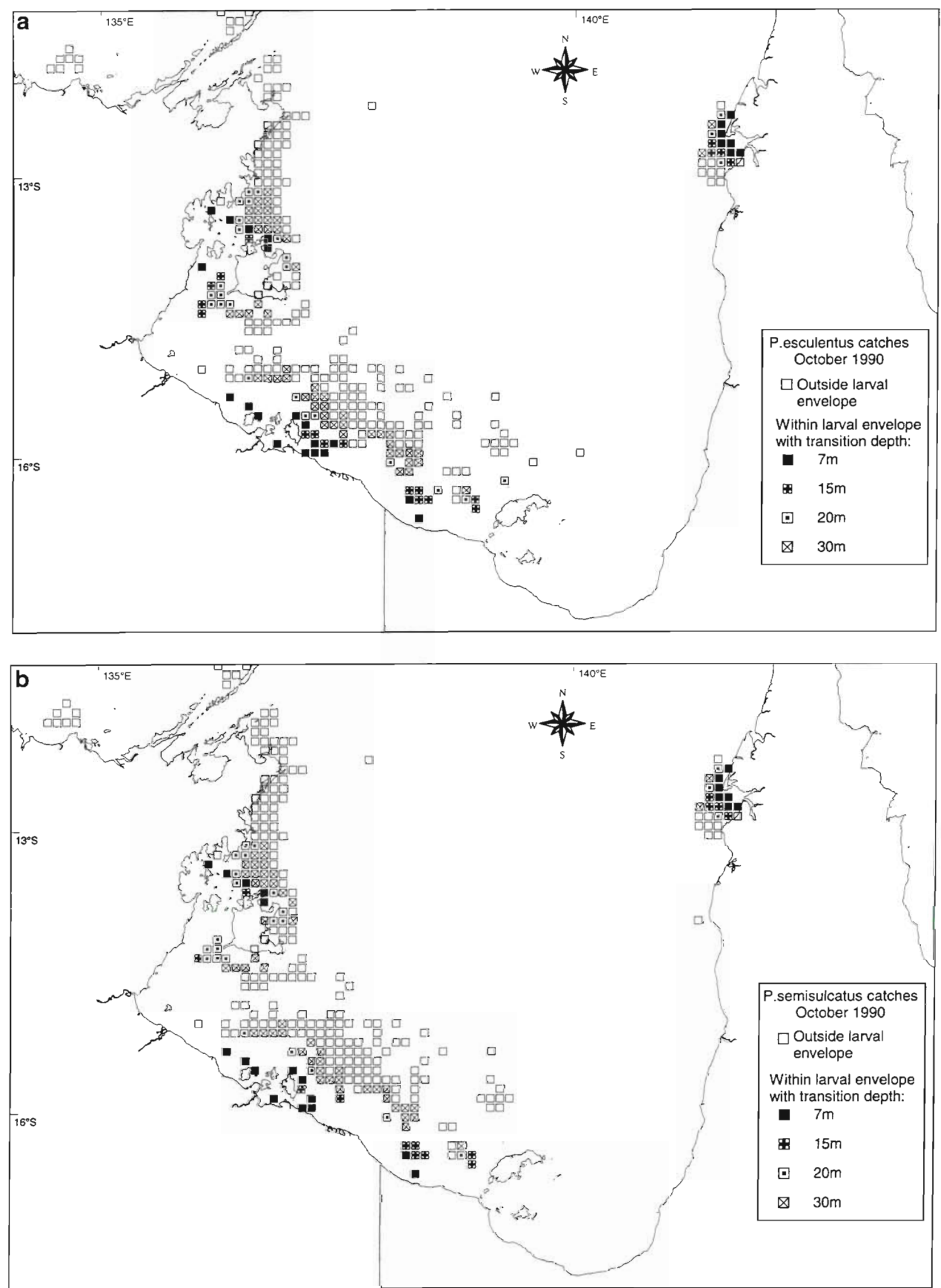
tive spawning areas were not, however, uniformly distributed around the Gulf of Carpentaria (Fig. 10). For example, in the northeast, the effective spawning area of $P$. semisulcatus was identified at both shallow and deep transition depths, whereas in the southwest an effective spawning area was only found when the deepest transition depth $(30 \mathrm{~m})$ was used.

\section{DISCUSSION}

\section{Variability}

The size and shape of the advection envelopes were largely determined by the tidal circulation in the Gulf of Carpentaria. They appear to be relatively insensitive to other aspects of the hydrodynamics. This is further supported by comparisons of our results with those for earlier modelling work in the Weipa region, using similar larval behaviour (Rothlisberg et al. 1996). For example, the envelopes in their Fig. 8c extend offshore and to the north, very similarly to those in our Fig. 4, despite differences between the models in grid resolution, flow dispersion and wind forcing.

The large seasonal fluctuations in the size of the advection envelopes can be attributed to tidal variations. However, the weak interannual variability in the size of the advection envelopes suggests that winds associated with synoptic-scale weather systems have limited influence. Winds during the main OctoberNovember spawning period are historically very weak and more variability might be expected in FebruaryMarch. However, the major interannual fluctuations observed in postlarval numbers entering the Albatross Bay estuaries at Weipa (Vance et al. 1996) must be a consequence of other factors. These may be associated with physical conditions not included in the model, such as localized storms, sea breezes, or unseasonal rainfall and freshwater inflow, or alternatively with biological factors that influence behaviour or mortality. The influence of the latter has been demonstrated by field experiments in Albatross Bay near Weipa, where the survival of Penaeus merguiensis larvae varied between 30 and $60 \%$ over a single $3 \mathrm{~d}$ period (Preston et al. 1992).

The very limited influence of wind contrasts sharply with other species which experience extended periods of non-tidal advection. For example, spring winds can explain the cross-shelf distribution of the Dungeness crab Cancer magister larvae, including their onshore transport to favourable settling areas (Botsford \& Hobbs 1995, McConnaughey et al. 1995).

\section{The role of larval behaviour}

The largest sources of uncertainty in predicting the size and shape of the advection envelopes are associated with the larval behaviour. The estimates of the size of the advection envelopes from the model were very sensitive to the choice of transition depth. The only constraints currently available are observations of the eastern king prawn Penaeus plebejus on the subtropical east coast of Australia which suggest that the transition depth for this species is less than $20 \mathrm{~m}$ (Rothlisberg et al. 1995). However, this limited data set is for a different species from a different region. Field and laboratory experiments are now being used to refine our estimates of the transition depth for tiger prawn postlarvae (D. J. Vance, CSIRO Marine Research, pers. comm.)

Following the change in behaviour from vertical migration cued by a diel signal to that cued by the flood tide, an additional uncertainty is associated with the time that postlarvae remain active during the flood tide. We assumed that they remain active for the entire flood tide, thereby maximizing the larval advection. This behaviour requires the larvae to start swimming in response to the increasing hydrostatic pressure at the start of the flood tide, then settle rapidly under the reduced turbulence conditions during the change of tide. However, it is equally plausible that they swim to the bottom after a certain period of activity. Rothlisberg et al. (1996) examined scenarios for 3 and 6 hourly activity around Weipa. They found that while the shorter activity period slowed the growth rate of the advection envelope, the growth continued for longer so that the envelope size after $28 \mathrm{~d}$ was similar in both scenarios. The main effect of a reduced activity period is therefore likely to be increased exposure to the higher offshore mortality.

Even after the larvae reach the nursery grounds, their behaviour can still influence the advection envelope. We assumed that the tidal swimming behaviour continues over the seagrass beds. In most regions, this simply clusters the larvae more tightly along the coastline without affecting the envelope. However, in a few locations, such as the northwest corner of Groote

Fig. 10. Distribution of spawning ( 6 ' grids representing $80 \%$ of the commercial catch) and effective spawning (spawning grids within the advection envelope) for (a) Penaeus esculentus and (b) P. semisulcatus and a range of transition depths 
Eylandt, the flood tides remove postlarvae from the seagrass beds. Laboratory studies have shown that postlarvae become more benthic once they reach a certain size and hence this assumption may not apply to large postlarvae ( $>1.6 \mathrm{~mm}$ carapace length, Liu \& Loneragan 1997).

\section{Effective spawning areas}

Because the area of effective spawning was partially defined by the larval advection envelopes, it was also highly sensitive to the transition depth of postlarvae. In some regions of the Gulf of Carpentaria, the distributions of catches overlapped with those of the advection envelopes only for the deepest transition depth $(30 \mathrm{~m})$. This suggests either that the real transition depth is relatively deep $(\geq 30 \mathrm{~m})$, or that a high proportion of the successful spawners are found closer to the coast, in regions outside the major fishing grounds.

It is well established that large tiger prawns, particularly grooved tiger prawns Penaeus semisulcatus, are not confined to the main fishing grounds and occur throughout the Gulf of Carpentaria, albeit in low densities (Crocos \& van der Velde 1995). There are also large areas of untrawlable ground, particularly around the islands of the western Gulf, such as the Vanderlins archipelago. Spawning tiger prawns may be abundant in these areas that are not accessible to the fleet and, therefore, do not appear in the catch or estimated spawning distributions. Shallow waters are closed to commercial fishing and may also contain some spawning prawns that are safe from fishing (e.g. Somers et al. 1987). Both the untrawlable grounds and the shallow areas would act as ecological refuges for spawning tiger prawns.

The main evidence against effective spawning being concentrated within untrawlable or shallow waters is that in the past fishing has strongly affected the recruitment of tiger prawns to the fishery (Wang \& Die 1996). While this does not preclude unfished areas from contributing significantly to the effective spawning population, it means either that the fishing grounds contribute to a large portion of the effective spawning or that fishing impacts spawning populations outside the trawling grounds. The latter can only occur if the population of spawners is thoroughly mixed in the areas within the advection envelopes. Unfortunately there is little information on mixing other than that obtained from tag-recaptures, which only applies to movements within the fishing grounds. Alternatively, if mixing within the advection envelopes was limited, then it would support the hypothesis that the transition depth is likely to be relatively deep (>30 m).
The distribution of effective spawning shown in Fig. 10 suggests that there is more than a single stock of tiger prawns in the Gulf of Carpentaria. There are large gaps in the effective spawning distribution for all the fishing grounds, and those in the northeast are particularly well isolated. The only mechanism for effective mixing of prawn populations would have to be the migration of adults across these gaps. There is strong evidence that the majority of prawns migrate over distances smaller than the width of the gaps (Somers \& Kirkwood 1991) and there is no evidence of excursions approaching the apparent separation of the effective spawning distributions. Our results suggest that there may be 3 main stocks of each of the 2 species of tiger prawns in the Gulf of Carpentaria. For Penaeus semisulcatus, the first stock is found in the northeast around Weipa, the second in the southwest, south of Groote Islandt, and the third to the northwest of Groote Eylandt. Penaeus esculentus would also have a northwest and southwest stock, with a third one in the southeast near Mornington Island.

\section{CONCLUSION}

The coupled hydrodynamic-larval model has provided advection envelopes for the entire Gulf of Carpentaria within the 5 yr period from 1986 to 1990 . The tides were by far the major hydrodynamic influence on the size and shape of the advection envelopes, and the seasonal cycle of the tides generated substantial seasonal variability in the advection envelopes. This contrasts with the effects of the broad-scale winds, which had a very limited influence on larval transport, resulting in low levels of interannual variability. Alternate explanations, presumably based on variation in mortality rates, are therefore required to account for the large interannual variability observed in postlarval numbers (Vance et al. 1996). Realistic levels of summertime stratification in the Gulf tend to maintain a well-mixed coastal zone and also have relatively little influence on postlarval advection. While the model was relatively robust to changes in the hydrodynamics, it was very sensitive to changes in the values of the parameters for larval behaviour. For example, it has been assumed that postlarvae remain within the water column for the duration of the flood tide. Shorter periods of activity will reduce the growth rate of the advection envelopes (Rothlisberg et al. 1996). However, by far the most sensitive and poorly constrained behavioural parameter is the transition depth at which larvae switch from vertical migration cued by the diel cycle to that cued by the tides. Improved estimates of this parameter are required to predict the advection envelopes with greater confidence. 
The present work challenges the current management dogma that the best way to reduce the impacts of fishing on spawning tiger prawns is to use seasonal closures. It may be possible to protect a large portion of the effective spawning stock by closing selected inshore areas within the main fishing grounds. It also questions the assumption that there is a single stock of each species of tiger prawns in the NPF. We suggest that in the Gulf of Carpentaria alone there are at least 3 substocks for each of the 2 species

Acknowledgements. This research was funded by the Fisheries Research and Development Corporation (FRDC 95/014). Discussions on larval behaviour with David Vance and Peter Rothlisberg were instrumental in the design of the larval model. We thank Peter Crocos, David Griffin, Peter Rothlisberg and David Vance for helpful comments on the manuscript. The hydrodynamic model, MECO, was developed at the CSIRO Division of Marine Research by Stephen Walker and Jason Waring.

\section{LITERATURE CITED}

Australian National Tide Tables (1996) Australian Government Publishing Service, Canberra

Botsford LW, Hobbs RC (1995) Recent advances in the understanding of cyclic behaviour of Dungeness crab (Cancer magister) populations. ICES mar Sci Symp 199:157-166

Church JA, Forbes AMG (1981) Non-linear model of the tides in the Gulf of Carpentaria. Aust J Mar Freshwat Res 32 : $685-697$

Crocos PJ, van der Velde TD (1995) Seasonal, spatial and interannual variability in the reproductive dynamics of the grooved tiger prawns, Penaeus semisulcatus de Haan, in Albatross Bay, Gulf of Carpentaria, Australia. Mar Biol $122: 557-570$

Csanady GT (1982) Circulation in the coastal ocean. D Reidel Publishing Company, Dordrecht

Dall W, Hill BJ, Rothlisberg PC, Staples DJ (1990) Biology of Penaeidae. Adv Mar Biol 27:1-461

Forbes AMG (1984) The contribution of local processes to the seasonal hydrology of the Gulf of Carpentaria. Oceanogr Trop 19:93-201

Gracia A (1996) White shrimp (Penaeus setiferus) recruitment overfishing. Mar Freshwat Res 47:59-65

Haywood MDE, Vance DJ \& Loneragan NR (1995) Seagrass and algal beds as nursery habitats for tiger prawns (Penaeus semisulcatus and $P$ esculentus) in a tropical Australian estuary. Mar Biol 122:213-223

Hughes DA (1969) Responses to salinity change as a tidal transport mechanism of pink shrimp, Penaeus duorarum. Biol Bull 136:43-53

Liu H, Loneragan NR (1997) Size and time of day affect the response of postlarvae and early juvenile grooved tiger prawns Penaeus semisulcatus De Haan (Decapoda: Penaeidae) to natural and artificial seagrass in the laboratory. J Exp Mar Biol Ecol 211:263-277

Loneragan NR, Kenyon RA, Staples DJ, Poiner IR, Conacher CA. (1998) The influence of seagrass type on the distribution and abundance of postlarval and juvenile tiger prawns (Penaeus esculentus and $P$. semisulcatus) in the western Gulf of Carpentaria, Australia. J Exp Mar Biol Ecol 228:175-196

McConnaughey RA, Armstrong DA, Hickey BM (1995) Dun- geness crab (Cancer magister) recruitment variability and Ekman transport of larvae. ICES Mar Sci Symp 199: $164-174$

O'Brien CJ (1994) Population dynamics of juvenile tiger prawns Penaeus esculentus in south Queensland, Australia. Mar Ecol Prog Ser 104:247-256

Olmi EJ III (1994) Vertical migration of blue crab Callinectes sapidus megalopae: implications for transport in estuaries. Mar Ecol Prog Ser 113:39-54

Penn JW, Caputi N (1986) Spawning stock recruitment relationships and environmental influences on the tiger prawn (Penaeus esculentus) fishery in Exmouth Gulf, western Australia. Aust J Mar Freshwat Res 37:491-505

Penn JW, Caputi N, Hall NG (1995) Stock-recruitment relationships for the tiger prawns (Penaeus esculentus) stocks in Western Australia. ICES Mar Sci Symp 199:320-333

Poiner IR, Staples DJ, Kenyon R (1987) Seagrass communities of the Gulf of Carpentaria, Australia. Aust J Mar Freshwat Res 38:121-131

Preston NP, Burford MA, Coman FE, Rothlisberg PC (1992) Natural diet of larval Penaeus merguiensis (Decapoda: Penaeidae) and its effect on survival. Mar Biol 113; 181-191

Rothlisberg PC (1982) Vertical migration and its effect on dispersal of penaeid shrimp larvae in the Gulf of Carpentaria, Australia. Fish Bull 80:541-554

Rothlisberg PC (1995) Postlarval recruitment dynamics and coastal oceanography used to estimate the spawning location of the eastern king prawn, Penaeus plebejus. In: Courtney AJ, Cosgrove MG (eds) Proceedings of the workshop on spawning stock-recruitment relationships (SRRs) in Australian crustacean fisheries. Queensland Department of Primary Industries Conference and Workshop Series QC95005. DPI, Brisbane, p 86-89

Rothlisberg PC. Church JA, Forbes AMG (1983) Modelling the advection of vertically migrating shrimp larvae. J Mar Res 44:511-538

Rothlisberg PC, Church JA, Fandry CB (1995) A mechanism for near-shore concentration and estuarine recruitment of post-larval Penaeus plebejus Hess (Decapoda, Penaeidae). Estuar Coast Shelf Sci 40:115-138

Rothlisberg PC, Craig PD, Andrewartha JR (1996) Modelling penaeid prawn larval advection in Albatross Bay, Australia: defining the effective spawning population. Mar Freshwat Res 47:157-168

Somers IF (1994) Species composition and distribution of commercial penaeid prawn catches in the Gulf of Carpentaria, Australia, in relation to depth and sediment type. Aust $\mathrm{J}$ Mar Freshwat Res 45:317-335

Somers IF, Kirkwood GP (1991) Population ecology of the grooved tiger prawn. Penaeus semisulcatus, in the northwestern Gulf of Carpentaria, Australia: growth, movement, age structure and infestation by the Bopyrid parasite Epipenaeon ingens. Aust J Mar Freshwat Res 42: $349-367$

Somers IF, Long BG (1994) Note on the sediments and hydrology of the Gulf of Carpentaria, Australia. Aust J Mar Freshwat Res 45:283-291

Somers IF, Crocos PJ, Hill BJ (1987) Distribution and abundance of the tiger prawns Penaeus esculentus and Penaeus semisulcatus in the north-western Gulf of Carpentaria, Australia. Aust J Mar Freshwat Res 38:63-78

Staples DJ, Vance DJ, Heales DS (1985) Habitat requirements of juvenile penaeid prawns and their relationship to offshore fisheries. In: Rothlisberg PC, Hill BJ, Staples DJ (eds) 2nd Aust Nat Prawn Sem, Cleveland, Australia. NPS2, Cleveland, p 47-54 
Vance DJ, Haywood MDE, Heales DS, Staples DJ (1996) Seasonal and annual variation in abundance of postlarval and juvenile grooved tiger prawns Penaeus semisulcatus and environmental variation in the Embley River, Australia: a six year study. Mar Ecol Prog Ser 135:43-55

Walker SJ (1996) Hydrodynamic models of Port Phillip Bay. Technical Report No. 38, CSIRO Port Phillip Bay Environ-

Editorial responsibility: Otto Kinne (Editor), Oldendorf/Luhe, Germany mental Study, Melbourne

Wang YG, Die DJ (1996) Stock-recruitment relationships of the tiger prawns (Penaeus esculents and Penaeus semisulcatus) in the Australian Northern Prawn Fishery. Mar Freshwat Res 47:87-95

Wolanski E (1993) Water circulation in the Gulf of Carpentaria. J Mar Syst 4:401-420

Submitted: June 17, 1998; Accepted: October 26, 1998 Proofs received from author(s): March 1, 1999 